\title{
Anatomical Variation of the Azygos System of Veins - Case Report
}

\author{
Josikwylkson Costa Brito ${ }^{1}$ Vlademir Lourenço Falcão Júnior ${ }^{1}$ Ana Luisa Castelo Branco Gomes ${ }^{1}$ \\ Deyvsom Felipe de Sousa Queiroga ${ }^{1}$ Luciana Karla Viana Barroso ${ }^{1,2}$
}

\author{
${ }^{1}$ Department of Morphology, Faculdade de Ciências Médicas de \\ Campina Grande, Centro de Ensino Superior e Desenvolvimento, \\ Campina Grande, PB, Brazil \\ ${ }^{2}$ Center for Biological and Health Sciences, Universidade Federal de \\ Campina Grande, Campina Grande, PB, Brazil
}

\begin{abstract}
Address for correspondence Josikwylkson Costa Brito, Departamento de Morfologia, Faculdade de Ciências Médicas de Campina Grande, Centro de Ensino Superior e Desenvolvimento, Av. Sen. Argemiro de Figueiredo, 1901 Sandra Cavalcante, Campina Grande - PB, 58411-020, PB, Brazil (e-mail: josikwylkson99@gmail.com).
\end{abstract}

J Morphol Sci 2019;36:207-209.

\begin{abstract}
Keywords

- azygos system

- anatomic variation

- thorax drainage

- vascular variation and macroscopic human anatomy.

Introduction The azygos system of veins (ASV) is a very variable structure characterized as a communication between the inferior and superior vena cava, having the azygos vein (AV), the hemiazygos vein (HV), and the accessory hemiazygos vein (HAV) as its main components, which are responsible for the mediastinal viscera and for the thoracoabdominal wall drainage. The aim of the present study is to report an anatomical variation found in a male cadaver at the Laboratory of Anatomy of the University Center of UNIFACISA, Campina Grande, PB, Brazil.

Case Report In the posterior mediastinum, the union of the HV, of the HAV, and of the $8^{\text {th }}$ left posterior intercostal vein formed a common trunk at the level of the left $8^{\text {th }}$ intercostal space, crossing the mediastinum posterior to the aorta artery, ending up in the $\mathrm{AV}$, in the right hemithorax.

Conclusion The study of the anatomical variations of the ASV is important and will provide knowledge for physicians not to confuse them with pathological processes in imaging exams. Moreover, it can provide safety in surgical approaches of the thorax.
\end{abstract}

\section{Introduction}

The azygos system of veins (ASV) is a pathway of collateral circulation between the superior and the inferior vena cava. ${ }^{1}$ It drains blood from the mediastinal viscera and from the thoracoabdominal wall, ${ }^{2}$ being even more relevant when a flow deficiency is present in the main veins that drain to the right atrium. ${ }^{1}$

Its basic constituents are the azygos vein (AV), the hemiazygos vein (HV), and the accessory hemiazygos vein (AHV). The system is found parallel to the vertebral column and is not followed by correspondent arteries. ${ }^{3}$

The AV and the HV are generally formed by the union of posterior branches of the inferior cava and/or renal veins with the ascending lumbar veins. The AV goes up at the right side of the vertebral column, finishing in the superior vena cava. The HV goes up at the left side of the vertebral column, crossing the mediastinum and going to the AV. The HAV starts in the left $4^{\text {th }}$ or $5^{\text {th }}$ intercostal space, going to the AV or to the HV. ${ }^{2}$

The ASV has been extensively studied, and anatomical variations on its constituents are not so rare. ${ }^{2,3}$ These variations differ from each other according to their origin, caliber, course, and termination. ${ }^{4,5}$ This fact can explain why there are so many attempts to classify the $A S V,{ }^{4,6-8}$ but there still is no consensus about these classifications.

The knowledge of the ASV is important to the medical practice because alterations on its structure can be confused with aneurysms, with mediastinal tumors, or with infarcted lymph nodes, ${ }^{9}$ leading to wrong interpretations of imaging exams. The present study reports an anatomical variation of the ASV found in a human male cadaver at the Laboratory of Anatomy of the University Center of UNIFACISA, Campina Grande, PB, Brazil. received

July 28, 2018

accepted

April 14, 2019
DOI https://doi.org/

10.1055/s-0039-1688976. ISSN 2177-0298.
Copyright $\odot 2019$ by Thieme Revinter

Publicações Ltda, Rio de Janeiro, Brazil
License terms

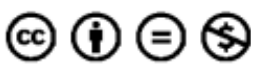




\section{Case Report}

During the study of a previously dissected human male cadaver, the anatomical variation found in the posterior mediastinum was the union of the HV, of the HAV, and of the 8th posterior intercostal veins, forming a common trunk situated in the left $8^{\text {th }}$ intercostal space. This trunk went from the left side across the posterior mediastinum to the right hemithorax, passing posterior to the thoracic aorta and communicating with the AV at the level of the right $8^{\text {th }}$ intercostal space. The other veins maintained their usual path, without any variations (- Figure 1).

\section{Discussion}

In the intrauterine life, the ASV develops from the subcardinal veins. The right subcardinal vein forms the AV, and the left subcardinal vein forms the HV. The HAV, as well as the superior part of the $A V$, originates from the left posterior cardinal vein. The connection between the HV and the AV originates from the anastomosis between the right and the left posterior cardinal veins. ${ }^{10}$

The HV and the HAV can form common channels that cross the posterior mediastinum. ${ }^{11}$ In our study, the HV and the HAV form a common trunk with the $8^{\text {th }}$ left posterior intercostal vein. A similar variant was already described, with only the HV and HAV veins forming a common trunk, without any participation of other veins. ${ }^{12}$

Also, it was found an "interazygos" vein originating from the HV, crossing the mediastinum anteriorly to the aorta artery and draining blood from the $7^{\text {th }}, 8^{\text {th }}, 9^{\text {th }}, 10^{\text {th }}$ and $11^{\text {th }}$ posterior intercostal veins. ${ }^{13}$ Another description is for an incomplete accessory HV with the posterior intercostal veins draining directly to the AV. ${ }^{14}$

A large number of studies show the absence of one or more components of the ASV, ${ }^{5,14-16}$ although no study has found any variation similar to the one presented in the present article. The HAV is the most variable component of the ASV in terms of absence, number of branches, communications, and level of termination. ${ }^{4}$ This is an important fact to take into

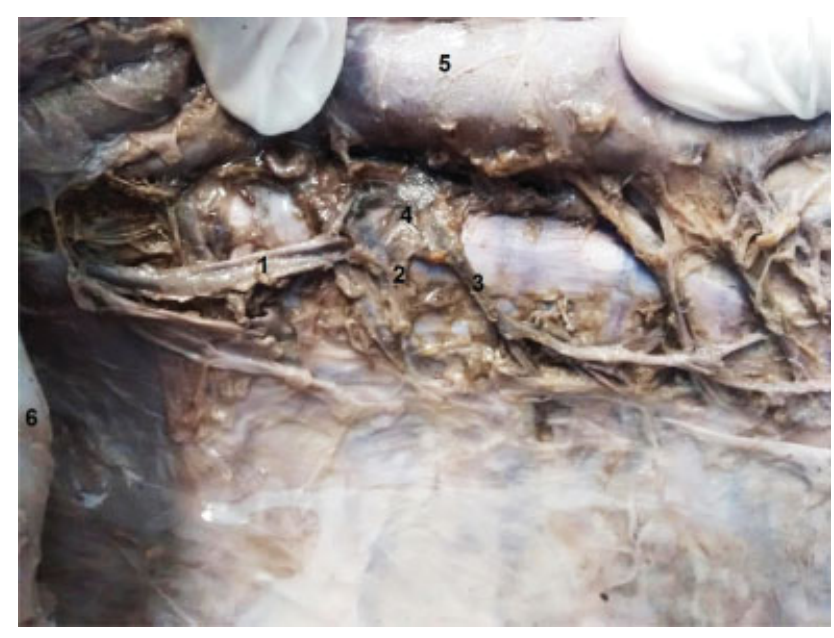

Fig. 11 hemiazygos vein; 2 , left $8^{\text {th }}$ posterior intercostal vein; 3 , accessory hemiazygos vein; 4 , common trunk; 5 , aorta artery; and 6 , diaphragm. consideration when accessing the vertebral column in surgical approaches, as the ability of recognizing the structures adjacent to the thoracic vertebral column, as well as their variations, is essential to a favorable outcome in these procedures. ${ }^{17}$

\section{Conclusion}

There are many variations in the ASV, and new ones must be reported and documented, since some of them can be misinterpreted as pathological processes such as aneurysms, enlarged lymph nodes, or tumors. Moreover, it is important for surgeons to have these variations in mind when surgically accessing the mediastinal region, preventing unforeseen scenarios.

Conflicts of Interests

The authors have no conflicts of interests to declare.

\section{References}

1 Piciucchi S, Barone D, Sanna S, et al. The Azygos Vein Pathway: An Overview From Anatomical Variations To Pathological Changes. Insights Imaging [online] 2014;5(05):619-628. Acessed February 14, 2017. Available at: https://goo.gl/EVD2nF

2 Moore KL, Dalley AF, Agur AMR. Anatomia Orientada para Clínica; translation: Claudia Lucia Caetano de Araujo. 7th ed. Rio de Janeiro: Guanabara Koogan; 2014:151-231

3 Shivanal U, Geethanjali HT. Anomalous azygos veins - its embryological basis and clinical significance. Int J Res Med Sci 2015;3 (09):2323-2326. Acessed February 14, 2017. Available at: https:// goo.gl/zb87ad

4 Kutoglu T, Turut M, Kocabiyik N, Ozan H, Yildirim M. Anatomical analysis of azygos vein system in human cadavers. Rom J Morphol Embryol 2012;53(04):1051-1056. Acessed February 15, 2017. Available at: https://goo.gl/gFPeox

5 Ozbek A, Dalçik C, Colak T, Dalçik H. Multiple variations of the azygos venous system. Surg Radiol Anat 1999;21(01):83-85. Acessed February 15, 2017. Available at: https://goo.gl/NUZQ5U

6 Seib GA. The azygos system of veins in American whites and American negroes, including observations on the inferior caval venous system. Am J Phys Anthropol 1934;19(01):39-163. Acessed February 15, 2017. Available at: https://goo.gl/S587Eq

7 Falla A, Preston F, Anson B. Classification and calibration of the azygos venous system in 100 specimens. Surg Gynecol Obstet 1963;116:405-412

8 Tatar I, Denk CC, Celik HH, et al. Anatomy of the azygos vein examined by computerized tomography imaging. Saudi Med J 2008;29(11):1585-1588

9 Celik HH, Sargon MF, Aldur MM, Cumhur M. An anomalous course of the interazygos vein [abstract]. Surg Radiol Anat 1996;18(01):61-62. Acessed February 15, 2017. Available at: https://goo.gl/EuiUPC

10 Stadring S. Gray's Anatomy: The Anatomical Basis of Clinical Practice. 40th ed. London: Churchill Livingstone Elsevier; 2008:207-208

11 Das S, Paul S. Preaortic interazygos vein: A case report. Braz J Morphol Sci 2004;21(03):141-143. Acessed February 15, 2017. Available at: https://goo.gl/rkaAxi

12 Blackmon JM, Franco A. Normal variants of the accessory hemiazygos vein. Br J Radiol 2011;84(1003):659-660. Acessed February 16, 2017. Availabe at: https://goo.gl/u16uBH

13 Pyrzowski J, Spodnik JH, Lewicka A, Popławska A, Wójcik S. A case of multiple abnormalities of the azygos venous system: a praeaortic interazygos vein [abstract]. Folia Morphol (Warsz) 2007;66 (04):353-355. Acessed February 16, 2017. Available at: https:// goo.gl/o9T6Gg 
14 Kocabiyik N, Kutoğlu T, Albay S, Yalçin B, Ozan H. Azygos vein system abnormality: case report. Gulhane Tip Derg 2006;78:180-182

15 Caggiati A, Barberini F. Partial agenesis of the azygos vein: a case report [abstract]. Ann Anat 1996;178(03):273-275. Acessed February 16, 2017. Available at: https://goo.gl/Lm4nUx

16 Quadros LS, Potu BK, Guru A, et al. Anomalous azygos venous system in a south Indian cadaver: a case report. Cases J 2009;
2:6746. Accessed February 16, 2017. Available at: https://goo.gl/ mFppLi

17 Dahran N, Soames R. Anatomical Variations of the Azygos Venous System: Classification and Clinical Relevance. Int J Morphol 2016; 34(03):1128-1136. Acessed February 16, 2017. Available at: https://goo.gl/uG2eNp 